\title{
Evaluation of Evapotranspiration Methods for Rice Yield Simulation in a Tropical River Basin
}

\author{
Sonam Sandeep Dash ${ }^{1}$, Subhankar Debnath ${ }^{2 *}$ and Madhusmita Behera ${ }^{3}$ \\ ${ }^{1}$ School of Water Resources, Indian Institute of Technology Kharagpur, India \\ ${ }^{2}$ Centurion University of Technology and Management, Odisha, India \\ ${ }^{3}$ Soil Conservation, Government of Odisha, Odisha, India \\ *Corresponding author
}

\begin{tabular}{l} 
K e y w o r d s \\
Evapotranspiration; \\
Hydrological \\
modeling; Rice \\
yield; River basin; \\
SWAT \\
\hline Article Info \\
$\begin{array}{l}\text { Accepted: } \\
18 \text { April } 2020 \\
\text { Available Online: } \\
10 \text { May } 2020\end{array}$ \\
\hline
\end{tabular}

\section{Introduction}

Evapotranspiration (ET) is one of the key factors that influences the crop growth, dry biomass production, and yield. To improve the crop water productivity, accurate estimation of ET during the crop growing phases is of utmost importance. Hence, advanced techniques of ET estimation continue to draw the attention of meteorology,

\begin{abstract}
A B S T R A C T
Rice is the world's most consumed cereal grain, making up the dietary staple food of more than 60 percent of the world's population. For agriculture dominated country like India, the assessment of rice yield is of utmost importance for policy makers in managing the food security and water resources. The present study evaluates the efficiency of Soil and Water Assessment Tool (SWAT) to simulate rice yield during both kharif and rabi seasons in Brahmani River basin, and subsequently, identifies the appropriate evapotranspiration estimation approach for accurate quantification of crop water requirement, and irrigation scheduling. The outcomes of this study revealed that the two crop-specific model parameters, i.e., maximum leaf area index and radiation use efficiency affect the rice yield to greater extent. The SWAT simulates the rice yield better in the kharif season with NSE estimates of 0.81 and 0.79 during the calibration and validation period, respectively as compared to the rabi season. The crop growth dynamics is better conceptualized by the physically based FAO-56 PM approach than the Priestley and Taylor method in the study area. The outcomes of the study could be useful for the hydrologist and agronomist in developing decision support system for irrigation water management and crop yield assessment.
\end{abstract}


manner. Therefore, quantification of ET for the rice crop is of great importance for proper irrigation management and assessment of itsyield. Numerous studies have been conducted on the ET estimation of rice crop using lysimeter (Shahrokhnia and Sepaskhah, 2013; $\mathrm{Xu}$ et al., 2017), water balance (Choudhury et al., 2007; Shao et al., 2014) based approaches. Since direct measurement of ET is cumbersome and costly, many indirect methods have been developed for ET estimation based on the easily available meteorological parameters, viz., temperature based (Hargreaves and Samani 1985), (ii) radiation based (Priestley and Taylor 1972), and (iii) combination method (FAO-56 Penman Monteith) (Allen et al., 1998). However, their use is limited to region specific applications and accuracy may be compromised based on the input data availability. In this context, the hydrological modeling based indirect ET estimation proved to be a suitable alternative (Dash et al., 2019; Padhiary et al., 2019). Keeping this in mind, an overarching goal and contribution of this study isi) to evaluate the efficiency of agrohydrological model Soil and Water Assessment Tool (SWAT)for simulating rice yield in tropical climate; and ii) to identify the appropriate ET estimation approach for accurate quantification of crop water requirement, and irrigation scheduling.

\section{Materilas and Methods}

\section{Study area}

The concerned study was carried out in a typical paddy-dominated sub-watershed of the Brahmani River basin (BRB), Odisha. The $\mathrm{BRB}$ is located between longitude $83^{\circ} 52^{\prime}$ to $87^{\circ} 30^{\prime} \mathrm{E}$ and latitude $20^{\circ} 28^{\prime}$ to $23^{\circ} 35^{\prime} \mathrm{N}$ constituting an area of $39,269 \mathrm{~km}^{2}$ (Fig. 1). The basin experiences highly undulated topography with elevation ranges between 1 to $1169 \mathrm{~m}$ above the mean sea level (MSL).The BRB is characterized by tropical monsoon climate which receives an average annual rainfall of $1305 \mathrm{~mm}$ with major portion $(70 \%)$ of rainfall is confined to the monsoon season (June-October). The BRB encompasses a diversified land use land/ land cover (LULC) distribution with cropland as the major LULC class constituting $52.04 \%$ of total basin area. The major stakeholders of the basin are completely dependent on the agriculture for their livelihood. Paddy is major crop grown in the BRB and cultivated twice in the year during the two major cropgrowing seasons. i.e., rabi and kharif.

\section{SWAT Model set up}

SWAT model is a physically based river basin scale model used widely for simulating streamflow, sediment yield, pollutant loading, and crop yield with utmost accuracy (Arnold et al., 1998). The SWAT model has an extensive spatial discretization scheme starting from sub-basin to Hydrological Response Unit (HRU) to account for the minimal variation in catchment hydrological conditions. The SWAT agro-hydrological model was set up for the concerned basin using the $30 \mathrm{~m}$ resolution ASTER digital elevation model (DEM), $1 \mathrm{~km}$ resolution soil map collected from FAO soil database, and daily meteorological inputs (Rainfall, maximum and minimum temperature) collected from the Indian Meteorological Department (IMD), Bhubaneswar. The daily reservoir outflow from the Rengali reservoir was used to model the irrigation requirement during the crop growing periods. The model simulation for seasonal rice yield estimation was carried out for the duration 1998-2010, with initial three years (1998-2000) as the model warm-up period in order to simulate initial model wetness. The seasonal rice yield during both rabi and kharif seasons were duly calibrated and validated for the period 20012006 and 2007-2010, respectively. The sensitivity analysis was performed prior to the calibration using the crop parameters of 
SWAT model. Further, the uncertainty was quantified by the 95 percent prediction uncertainty (PPU) plot derived P-factor and R-factor magnitude (Dash et al., 2020).

\section{ET scenarios for crop yield}

ET is main driving factor that quantifies irrigation requirement during different growth phases; thereby affects the crop yield significantly. Hence accurate estimation of ET for crop yield estimation is highly essential. The chosen ET estimation algorithm in the SWAT model alters the water balance of the simulated hydrological fluxes substantially. The simulation of rice yield isquantified under twoglobal ET estimation scenario, i.e., FAO-56 Penman Monteith (PM) and Priestley Taylor (PT) approach as given below Eqs. (1) and (2), respectively:

$$
\lambda E=\frac{\Delta \cdot\left(H_{n e t}-G\right)+\rho_{a i r} \cdot c_{p} \cdot\left[e_{z}^{o}-e_{z}\right] / r_{a}}{\Delta+\gamma \cdot\left(1+r_{c} / r_{a}\right)}
$$

where $\lambda E$ is the latent heat flux density (MJ $\left.\mathrm{m}^{-2} \mathrm{~d}^{-1}\right), E$ is the depth rate evaporation (mm $\left.\mathrm{d}^{-1}\right), \Delta$ is the slope of the saturation vapor pressure-temperature curve, de/dT $\left(\mathrm{kPa}^{\circ} \mathrm{C}^{-1}\right)$, $H_{\text {net }}$ is the net radiation $\left(\mathrm{MJ} \mathrm{m}^{-2} \mathrm{~d}^{-1}\right), G$ is the heat flux density to the ground $\left(\mathrm{MJ} \mathrm{m}^{-2} \mathrm{~d}^{-1}\right)$, $\rho_{\text {air }}$ is the air density $\left(\mathrm{kg} \mathrm{m}^{-3}\right), c_{p}$ is the specific heat at constant pressure $\left(\mathrm{MJ} \mathrm{kg}^{-1}{ }^{\circ} \mathrm{C}^{-}\right.$ $\left.{ }^{1}\right), e_{z}^{o}$ is the saturation vapor pressure of air at height $z(\mathrm{kPa}), e_{z}$ is the water vapor pressure of air at height $z(\mathrm{kPa}), \gamma$ is the psychrometric constant $\left(\mathrm{kPa}{ }^{\circ} \mathrm{C}^{-1}\right), r_{c}$ is the plant canopy resistance $\left(\mathrm{s} \mathrm{m}^{-1}\right)$, and $r_{a}$ is the diffusion resistance of the air layer (aerodynamic resistance) $\left(\mathrm{s} \mathrm{m}^{-1}\right)$.

$$
\lambda E_{o}=\alpha_{p e t} \cdot \frac{\Delta}{\Delta+\gamma} \cdot\left(H_{n e t}-G\right)
$$

where $\lambda$ is the latent heat of vaporization (MJ $\left.\mathrm{kg}^{-1}\right), E_{o}$ is the potential evapotranspiration $\left(\mathrm{mm} \mathrm{d}^{-1}\right), \alpha_{p e t}$ is a coefficient, $\Delta$ is the slope of the saturation vapor pressure-temperature curve, $d e / d T\left(\mathrm{kPa}^{\circ} \mathrm{C}^{-1}\right), \gamma$ is the psychrometric constant $\left(\mathrm{kPa}{ }^{\circ} \mathrm{C}^{-1}\right), H_{\text {net }}$ is the net radiation $\left(\mathrm{MJ} \mathrm{m}^{-2} \mathrm{~d}^{-1}\right.$ ), and $G$ is the heat flux density to the ground $\left(\mathrm{MJ} \mathrm{m}^{-2} \mathrm{~d}^{-1}\right)$.

\section{Performance evaluation criteria}

The efficiency of the SWAT model in simulating the rice yield during both the growing seasons with respect to the observed crop yield values was evaluated by widely used measures of goodness of fit indices, such as Nash and Sutcliffe Efficiency (NSE) (Nash et al., 1970), coefficient of determination $\left(\mathrm{R}^{2}\right)$, and percent bias (PBIAS) as given below:

$$
\begin{aligned}
& N S E=1-\frac{\sum_{i=1}^{n}\left(O_{i}-P_{i}\right)^{2}}{\sum_{i=1}^{n}\left(O_{i}-O^{\prime}\right)^{2}} \\
& R^{2}=\left\{\frac{\left(\sum_{i=1}^{n}\left(O_{i}-O^{\prime}\right)\left(P_{i}-P^{\prime}\right)\right)^{2}}{\sum_{i=1}^{n}\left(O_{i}-O^{\prime}\right)^{2} \sum_{i=1}^{n}\left(P_{i}-P^{\prime}\right)^{2}}\right\} \\
& \text { PBIAS }=\frac{\sum_{i=1}^{n}\left(O_{i}-P_{i}\right)}{\sum_{i=1}^{n} O_{i}} \times 100
\end{aligned}
$$

where $n$ is total number of observed data, $O_{i}$ and $P_{i}$ are observed and simulated data at time $i, O^{\prime}$ and $P^{\prime}$ are the mean of observed and simulated data. The value of NSE close to one corresponds to better agreement between the observed and simulated yield values and viceversa.

Further, the ET estimation scenario which represented relatively lower disagreement between the observed and simulated yield 
value will be treated as the best ET estimation approach to enhance further the quantification of crop water requirement, and irrigation scheduling.

\section{Results and Discussion}

\section{Model calibration and validation}

The SWAT model sensitivity analysis was performed for the top ten crop parameters followed by the calibration and validation of seasonal rice yield simulation. The sensitivity analysis revealed that maximum leaf area index (BLAI) and radiation use efficiency (BIO_E) are the two sensitive most parameters that affect the rice yield to greater extent. The annual rice yield variation across the BRB during two crop growing season is presented in Fig. 2. As envisaged from Fig.2 the rabi season rice yield is always higher than that of the kharif season.

Moreover, reduced yield estimates during the year 2005 and 2006 could be consequence as a result of significant drop in the rainfall magnitude. The goodness of fit statistics of seasonal rice yield simulation is presented in Table 1. It can be elucidated that the SWAT simulates the rice yield better during the kharif season as evidenced from the NSE estimates of 0.81 and 0.79 during the calibration and validation periods, whereas the corresponding rabi season NSE estimates reduced to 0.77 .

The degree of mismatch between the yield is intensified during the mod-season stage of rice growth. This could be attributed to the inability of the SWAT model to account for sever moisture stress scenario of the rabi season. Furthermore, the RMSE estimates of $0.256 \mathrm{t} / \mathrm{ha}$ during the rabi season revealed that substantial reduction in rice yield could be caused due to the reduced irrigation application consequenced due to incorrect quantification of ET. Alternatively, during less severe moisture stress scenario of the kharif season, the RMSE estimates substantially reduces to $0.116 \mathrm{t} / \mathrm{ha}$.

\section{Implications of ET methods on rice yield assessment}

To analyze the implications of ET selection method on crop yield simulation, the annual ET estimates were quantified and presented in Fig. 3. As envisaged from the Fig. 3, the average annual (2001-2010) ET estimates simulated by the FAO-56 PM and PT are 900.59 \pm 123.32 and 812.21 $\pm 101.24 \mathrm{~mm}$, respectively, signifying considerable discrepancy between the two ET estimation approaches.

Moreover, the PET to ET conversion ratio was $46.62 \%$ for FAO-56 PM approach and the corresponding ratio was $62.21 \%$ for PT approach. The increased PET to ET conversion ratio for the PT approach corresponded to erroneous assessment of remaining water balance components of paddy field. This water balance could have resulted lower plant water availability for uptake by the plant roots. This process further gets aggravated during the mid-season stage of crop growth resulting reduced estimation of plant water uptake; thereby the model simulated irrigation water becomes unable to fulfill the crop water demand.

Moreover, the crop yield statistics revealed that the kharif season simulated yield under FAO-56 PM and PT scenario are 1.488 and $1.242 \mathrm{t} / \mathrm{ha}$, respectively, with respect to the observed yield magnitude of $1.674 \mathrm{t} / \mathrm{ha}$. Similarly, during the rabi season, observed, FAO-56 PM, and PT- based yield estimates are $2.456,2.298$, and $2.014 \mathrm{t} / \mathrm{ha}$, respectively, signifying the rabi season yield estimation uncertainties are higher than that of kharif season. 
As crop yield is affected the most by the plant water availability to fulfil the physiological requirement of crop, the accurate quantification of growth-stage specific ET is highly imperative. The outcomes of this study revealed that although the overall magnitude of ET is lower in case of FAO-56 PM approach, the crop growth dynamics is better conceptualized by the physically based FAO56 PM approach.

Moreover, the PT approach triggers irrigation application during the non-essential phases of crop growth; thereby results substantial reduction in the crop yield. Hence, for tropical monsoon climatic regions, FAO-56 PM approach can be treated as the best measure to quantify the crop water requirement to implement further water management operations. Nevertheless, the validity of the PT approach in crop yield estimation could be examined further under varying climatic conditions.

Table.1 Performance evaluation of rice crop yield during rabi and kharif season of BRB

\begin{tabular}{|l|c|c|c|c|}
\hline \multirow{2}{*}{ Indices } & \multicolumn{2}{|c|}{ Rabi } & \multicolumn{2}{c|}{ Kharif } \\
\hline NSE (-) & Calibration & Validation & Calibration & Validation \\
\hline R (-) & 0.77 & 0.72 & 0.81 & 0.79 \\
\hline RMSE (t/ha) & 0.84 & 0.86 & 0.91 & 0.89 \\
\hline
\end{tabular}

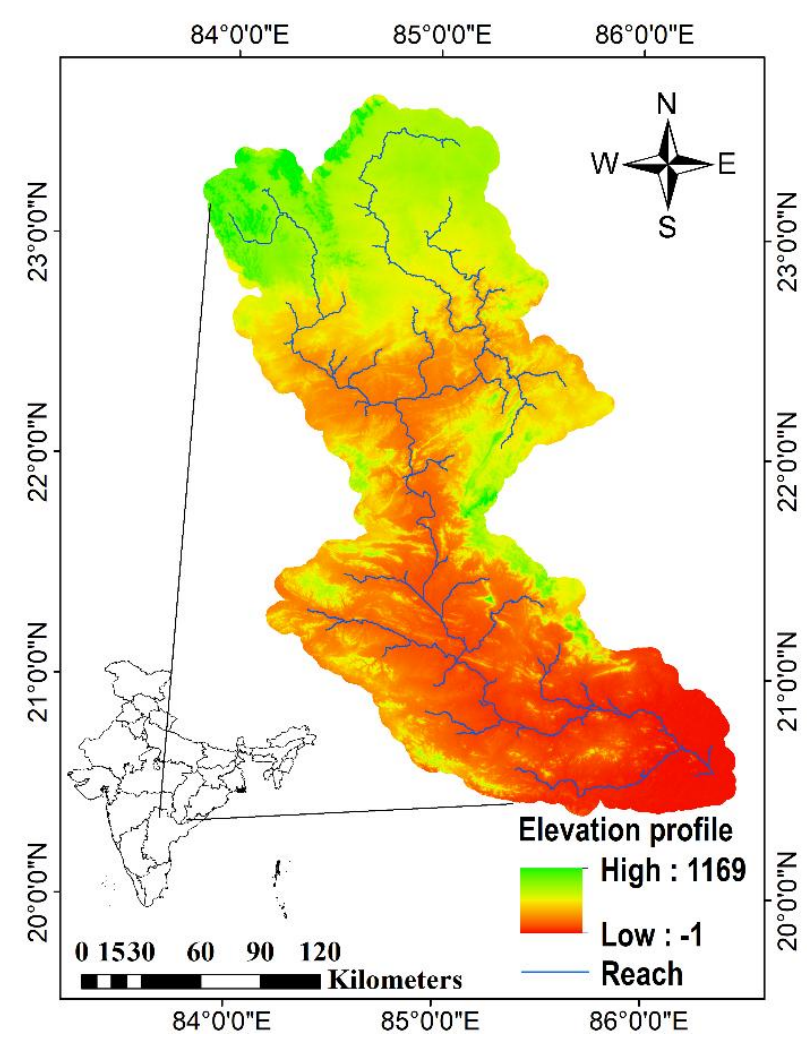

Fig.1 Index map of Brahmani River basin 


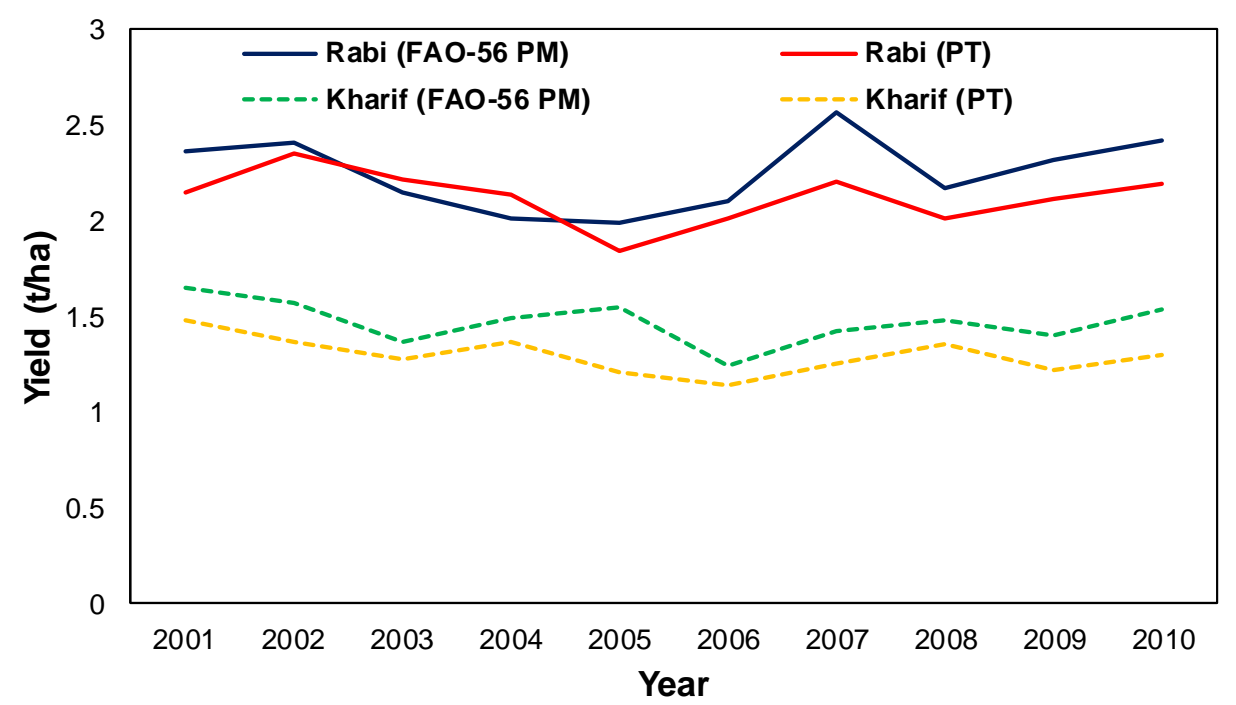

Fig.2 Reproduction of seasonal rice yield in the BRB for the period 2001-2010

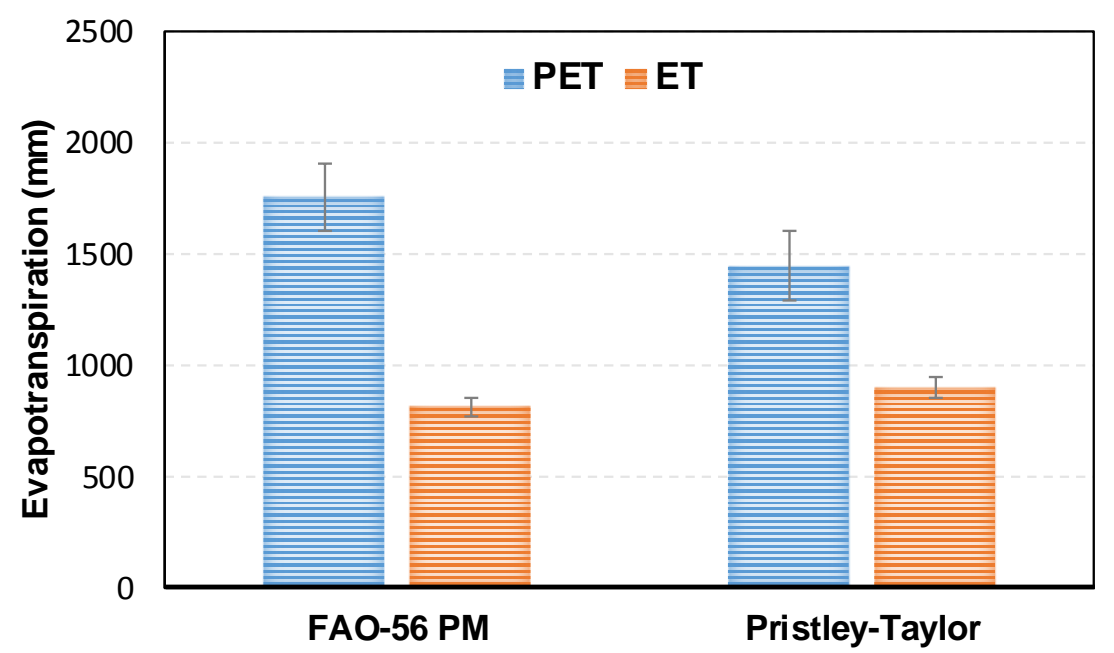

Fig.3 Average annual ET estimation by FAO-56 PM and Priestley-Taylor approach for the period 2001-2010

This study addresses an important concern regarding the effect of appropriate ET selection method on rice yield. The following conclusions are drawn from this study:

The SWAT is capable of reproducing the rice yield dynamics with utmost accuracy.

The uncertainty in rice yield simulation is higher during the rabi season as result of severe moisture stress scenario.

Out of the two considered ET scenario, the
FAO-56 PM approach represents the rice yield scenario with a more realistic manner.

\section{References}

Allen, R.G., Pereira, L.S., Raes, D., Smith, M., 1998. Crop evapotranspiration. FAO Irrigation and Drainage Paper 56, Food and Agricultural Organization of the United Nations, Rome.p. 300.

Arnold, J. G., Srinivasan, R., Muttiah, R. S., Willams, J. R., 1998. Large area hydrologic modeling and assessment - 
part I: model development. J. Am. Water Resour. Assoc. 34 (1), 73-89.

Choudhury, B. U., Bouman, B. A. M., and Singh, A. K. (2007). Yield and water productivity of rice-wheat on raised beds at New Delhi, India. Field Crops Research, 100(2-3), 229-239.

Dash, S. S., Sahoo, B., Raghuwanshi, N. S., 2018. Comparative Assessment of Model Uncertainties in Streamflow Estimation from a Paddy-Dominated Integrated Catchment-Reservoir Command. Wsahington D.C., AGU Fall Meeting.

Dash, S. S., Sahoo, B., Raghuwanshi, N. S., 2019. A SWAT-Copula based approach for monitoring and assessment of drought propagation in an irrigation command. Ecological Engineering. 127. https://doi.org/10.1016/j.ecoleng.2018.1 1.021.

Dash, S. S.,Sena, D. R., Mandal, U., Kumar A., Kumar, G., Mishra, P.K., Rawat, M., 2020. A hydrological modellingbased approach for vulnerable area identification under changing climate scenarios. Journal of Water and Climate Change,https://doi.org/10.2166/wcc.202 0.202 .

Hargreaves, G. H., and Samani, Z. A. (1985). Reference crop evapotranspiration from temperature. Applied engineering in agriculture, 1(2), 96-99.
Padhiary, J., Patra, K. C., Dash, S.S., and Kumar, A. U., 2019. Climate change impact assessment on hydrological fluxes based on ensemble GCM outputs: a case study in eastern Indian River Basin. Journal of Water and Climate

Change,https://doi.org/10.2166/wcc.201 9.080 .

Priestley, C. H. B., and Taylor, R. J. (1972). On the assessment of surface heat flux and evaporation using large-scale parameters. Monthly weather review, 100(2), 81-92.

Shahrokhnia, M. H., and Sepaskhah, A. R. (2013). Single and dual crop coefficients and crop evapotranspiration for wheat and maize in a semi-arid region. Theoretical and applied climatology, 114(3-4), 495-510.

Shao, G. C., Deng, S., Liu, N., Yu, S. E., Wang, M. H., and She, D. L. (2014). Effects of controlled irrigation and drainage on growth, grain yield and water use in paddy rice. European Journal of Agronomy, 53, 1-9.

Xu, J., Lv, Y., Ai, L., Yang, S., He, Y., and Dalson, T. (2017). Validation of dualcrop coefficient method for calculation of rice evapotranspiration under dryingwetting cycle condition. Paddy and water environment, 15(2), 381-393.

\section{How to cite this article:}

Sonam Sandeep Dash, Subhankar Debnath and Madhusmita Behera. 2020. Evaluation of Evapotranspiration Methods for Rice Yield Simulation in a Tropical River Basin. Int.J.Curr.Microbiol.App.Sci. 9(05): 2560-2566. doi: https://doi.org/10.20546/ijcmas.2020.905.292 